\title{
Fictional Names: Reference, Definiteness and Ontology
}

\author{
Mark Sainsbury*
}

Received: 26 February 2020 / Accepted: 18 June 2020

\begin{abstract}
Definite linguistic expressions, for example proper names and singular and plural pronouns, are easy to introduce. Indefinite expressions may pave the way, but are not essential. It is also not essential that there be entities to which the successfully introduced definites refer. This is the underlying fact that makes fiction possible, and it gives guidance about fictional names: we have no need in general to suppose that there exist entities to which they refer.
\end{abstract}

Keywords: Fiction, discourse representation theory, ontology.

\section{Discourse referents and speculation}

... the appearance of an indefinite noun phrase establishes a discourse referent just in case it justifies the occurrence of a coreferential pronoun or a definite noun phrase later in the text.... We maintain that the problem of coreference within a discourse is a linguistic problem and can be studied independently of any general theory of extra-linguistic reference. (Kartunnen 1976)

Kartunnen is focused on the way in which an indefinite noun phrase can "justify" a subsequent definite one, as in the classic example "A man came

* University of Texas at Austin

(iD) https://orcid.org/0000-0001-9030-9770

- Department of Philosophy, University of Texas at Austin, 2210 Speedway, Stop C3500 WAG 316, Austin, Texas 78712-1737

$\triangle$ marksainsbury@austin.utexas.edu

(C) The Author. Journal compilation (C) The Editorial Board, Organon F.

This article is distributed under the terms of the Creative Commons Attribution-NonCommercial 4.0 International Public License (CC BY-NC 4.0). 
into the bar. He ordered a martini". A singular pronoun like "he" is normally supposed to refer to a specific (male) person, and it is natural to suppose that understanding a token of the pronoun requires knowing what it refers to. In a sense, we do know what this occurrence of "he" refers to: the man who came into the bar. But more demanding tests for knowledge of reference may fail: we may have no further information to offer concerning the man, and we might be unable to distinguish him from other men. Since we understand the classic two-sentence example perfectly well, including its occurrence of "he", these failures show that the tests for understanding were overdemanding: understanding a definite pronoun does requires neither any substantive ability to distinguish its referent from other things nor the possession of further information concerning the referent. Furthermore, our understanding is not undermined by our ignorance of whether the two sentences are true, and whether they were uttered with full assertive seriousness, or with some non-truth-involving intention. Understanding does not require that we believe that there exists a real referent for "he", or even that we believe the utterer believes this or wants us to believe it.

A discourse referent, as I understand its role in Kartunnen's theory, and in the Discourse Representation Theories his work inspired, is a definite mental representational vehicle, singular or plural. There may or may not be some entity or entities to which it refers (so the expression "discourse referent" is somewhat misleading ${ }^{1}$ ). When hearers encounter an indefinite noun phrase like "a man" or "some men", they should introduce a discourse referent as a precaution: in case there are subsequent anaphorically dependent pronouns, as in the classic example or its plural form: "Some men came

1 See Kamp (1981), and the large subsequent research program. Kamp is clear that a discourse referent is a representation, not something represented; for example, he speaks of "a formula in which the predicate is combined with the chosen discourse referent" (Kamp and Reyle 1993: 61). Likewise the SEP entry on Discourse Representation Theory says that a Discourse Representation is a mental representation of which discourse referents are a part. (https://plato.stanford.edu/entries/discourserepresentation-theory/, §3.1). Mental representations, like everything else that really exists, are metaphysically definite things, though they may, like an indefinite noun phrase, be indefinite in how they represent. 
into the bar. They ordered martinis". The discourse referent introduced in the interpretation of the indefinite is then in place to interpret the pronoun. This structure can be used to ensure the intuitively correct truth conditions: the two sentences in the classic example are true iff there is a man who came into the bar and ordered a martini; the discourse referent registers these facts, and their analog for the plural case. Despite the definite character of the pronoun, the sentences do not require it to have a referent. As Kartunnen says, no "general theory of extra-linguistic reference" is needed. He illustrates the point by making the following comparison. The two sentences that follow pose just the same problem of understanding:

Bill saw a horse. It had a gold mane.

Bill saw a unicorn. It had a gold mane.

According to Kartunnen, the mechanism employed by an understander is the same in the two cases. Encountering the indefinite in the first sentence, a discourse referent is introduced. This is then available for interpreting the definite pronoun in the second sentence. As everyone would agree, truth requires there being a gold-maned horse (in the one case) or a gold-maned unicorn (in the other). Ontological matters only enter the story when we consider truth. Since fiction is not aimed at truth, ontological matters are not likely to enter at the level of understanding fiction.

Discourse referents are what make possible the use of definite expressions in speculations which leave open whether they have referents. Speculation is more closely connected to truth than fiction, but developing a speculation is independent of its evaluation for truth. One form of backward-looking speculation seeks explanations. The detective plays out various possible scenarios that could have resulted in the primary evidence: a murdered body. Who could have done it? Perhaps a business rival. But would he really have resorted to murder? Who had a motive? His heirs? Who were they? How would the murderer have got to the right place? Maybe it was a woman, and she had an appointment - better check the call log. The speculations involving pronouns (as italicized) come without any commitment to their really having a referent. As the evidence accumulates, some scenarios will be rejected. In favorable cases, all but one will be excluded. 
Forward-looking speculation is used in planning. One can review a range of possible things one might do. Shall I get a new attorney? He would need to be a member of a large practice. Or maybe I should hire a woman: she might be more understanding. Should we get some dogs? Maybe they should be lurchers. Or maybe poodles. But a pair of them would be too much to care for. Typically, at most one from among many scenarios which address the same issue is selected.

Whether we are trying to reconstruct the past or plan for the future, scenarios are essential, and as we entertain them we know that many or most are not factual, and that there are likely no referents for many of the definite expressions we use. Yet there is no problem about the intelligibility or metaphysics of the rejected scenarios. Intelligibility is mediated by the introduction of discourse referents, and these make no metaphysical demands. This humble ability to think about what is not yet the case and might never become the case, or about what might never have been the case, is the basis for fictional understanding. It is the key to the semantics and metaphysics of fiction. Its origins lie not in special conventions, but in the abilities we inevitably bring to bear when we explain and plan, both of which involve portraying non-factual scenarios, but neither of which counts as creating a work of fiction.

The use of definite expressions in speculation is a good guide to understanding the use of definite expressions, especially names, in fiction.

\section{Fictional reference: A quietist view}

One way to introduce a fictional name is by using generality as a preface, as in this typical example of an initial sentence:

There was a boy called Eustace Clarence Scrubb, and he almost deserved

it. ... Eustace Clarence liked animals.... (C. S. Lewis, The Voyage of the Dawn Treader)

The general expression ("There was a boy") paves the way, inviting the introduction of a discourse referent, and makes the introduction of the fictional name as utterly straightforward as if it had been an anaphoric pronoun. 
No such general preface is required. We can go straight into the story, as illustrated in this initial sentence:

Selden paused in surprise. (Edith Wharton, The House of Mirth.) ${ }^{2}$

We simply and automatically imagine a referent for "Selden", and the tense of the verb requires us to imagine some past time, or period of time. The phenomenon is not specific to fiction. A serious history might start by using the name of one of the persons whose actions are being described, even if the historian knows quite well that few of her readers will have encountered the person before. ${ }^{3}$ When we encounter a name, we in some sense "supply" a referent. This section aims to say more about what this "supplying" amounts to.

Pronouns, too, can be introduced with no advance warning, as in this initial sentence:

Now I believe they will leave me alone. (Wallace Stegner, Angle of Repose.)

With no preparation, the reader has to supply imaginary referents for the two singular pronouns and the one plural one. Three pronouns effortlessly engage our imagination's reference-supplying powers. And we need to supply an earlier time, not our own present ${ }^{4}$, for the "now".

Supplying a referent typically does not consist in selecting from among a stock of already available referents. The reader, and not just the author, needs to engage in an imaginative act: making up a referent. Typically, the early outlines will be dim, waiting to be filled as the story progresses. Details are added, and sometimes revised. In successful cases, readers will come to feel they know a fictional character as well as they know some of

2 The immediately following sentence of the novel gives us another unfamiliar name: "In the afternoon rush of the Grand Central Station, his eyes had been refreshed by the sight of Miss Lily Barr". Perhaps "Grand Central Station" counts as a complex name, and for many readers interpreting it will not require the use of an imagination-specific skill. Interpretation will be equally effortless and automatic.

3 "Virginia's first charter was prepared in the office of Attorney General Edward Coke, a sour-tempered man with a pointed chin ..." (Jill Lepore These Truths 34).

4 This results from our knowledge of such facts as that an encounter with a written text on a page occurs later than its initial utterance.

Organon F 28 (1) 2021: 44-59 
their own friends. The procedure seems platitudinously straightforward. What philosophical problems, semantic or metaphysical, could this process generate?

The idea of supplying an imaginary referent was intended to sound straightforward. "Selden" sounds like a man's name; let's start by assuming this is so, and use the name to collect further information. We are instantly able to use the name in thought. We can wonder how old Selden is, whether he is married, what surprised him, and so on. The conventions of fictional narrative ensure that we are unlikely to be disappointed: it is very unlikely, though not impossible, that it will turn out in the story that there is no such person as Selden, or that he has an indistinguishable double going by the same name. It's true that, after reading just a few sentences, we don't have a great deal to say if asked who Selden is, but that can be the same in the case of an early encounter with a non-fictional name. If readers can use a name in thought, they understand it. In a sense, they know to whom "Selden" refers, namely Selden. This knowledge is as helpful or unhelpful (depending in one's views about understanding) as the knowledge that "Texas" refers to Texas, knowledge lacked by those entirely ignorant of the geography of the USA.

Given that a name can be successfully introduced without any preamble, it is not surprising that a general preamble can enable the introduction of an anaphoric pronoun, as in the example from C. S. Lewis ("There was a boy... he ..."). The same mechanism is at work in both cases. We've seen how an indefinite can prompt the introduction of a discourse referent. A new name does likewise. "Making up" or "supplying" a referent, understood in a leaden and literal way, is something we could not do: we have no spare persons on hand to supply, and our reaction cannot count as literally creating a person. All that happens is that we introduce a representation of an appropriate definite kind, a discourse referent, and hold it in readiness for further use. This kind of mental act occurs both when we encounter fiction and when we encounter non-fiction.

A crucial presupposition of the adequacy of this answer is that there may be nothing that a coherent representation, usable in thought, represents. This may sound paradoxical: a non-representing representation? But it is commonplace. "Pegasus" represents Pegasus, "Vulcan" represents 
Vulcan; the painting represents a purely imaginary landscape. There are more complex examples: "If I were to get a dog, which I know I never will, it would be a poodle." If we take the sentence to be true, "it" represents a dog; or, as we might say, represents nothing.

The choice between $d o g$ and nothing corresponds to two ways in which "semantic" words like "represents", "refers" and "about" may be understood. These are all syntactically relational, having forms like "x represents/refers to/is about y. But in ordinary English, I claim, they are not semantically relational: the truth of such claims does not require a relation between two entities, as shown by such truths as "Pegasus' refers to Pegasus", and "We are thinking about unicorns". As I will put it, these words are only "weakly" relational. ${ }^{5}$

Some theorists, however, take such words to be strongly relational, in that truth of the relevant sentences does require a relation between two entities. I will mark this usage by an asterisk. Thus "Pegasus' refers* to Pegasus" is false if there is no such thing as Pegasus, and so is "We are thinking about* unicorns". If $\mathrm{x}$ represents* $\mathrm{y}$, there really is some entity, $\mathrm{y}$, that $\mathrm{x}$ represents, but the weak reading, "x represents $\mathrm{y}$ ", does not have this entailment. Although " $\mathrm{x}$ represents* $\mathrm{y}$ " entails " $\mathrm{x}$ represents $\mathrm{y}$ " the converse entailment fails. One could connect the ideas by saying that representation is purported representation*. Reverting to our example of wanting a dog, the "it" represents* nothing (at least if the remark is true), but represents a dog.

Representation or reference is an intuitive notion, more so than asterisked analogs, as the examples have shown. Unasterisked notions are the ones to which we must appeal to explain how we can interpret a new name: by introducing a discourse referent, a mental representational vehicle that refers to what the name refers to. The condition of co-reference is, of course, met if there is co-reference*, but this is no more required than reference* is.

Interpreting a sentence involving a past tense requires one to "imagine some specific past time, or period of time" as relevant. But relevant in what way? If the sentence is known to be fictional, the relevance is not to the truth of the sentence, for author and reader know quite well that truth is

$5 \quad$ For further support see Sainsbury (2018) and D'Ambrosio (2019). 
not at issue. We learn that some event we are asked to imagine should be imagined as lying in the past. But that does not give us a referent: there is no time concerning which we are asked to imagine it is the time the event took place.

This is no more puzzling than the role of the past tense in non-fictional utterances. If someone tells you she visited India, you know that, if what she said is true, a visit lies in the past. The utterance itself gives no basis for assigning one past time rather than any of the others during which the speaker was alive. On the other hand, it's not right to say that all you have available is knowledge that a visit lies in the past, so that the past tense really amounts to no more than "before now". For the presumed time can become an index for evaluating related utterances, as in "Then I spent a couple of days in Hawaii." If what the speaker said is true, there's a period of time she spent in India, and subsequent to that time she went to Hawaii. In order to express what we understand we need an apparently referential expression "that time". The past tense is typically indefinite, and then it works like any other indefinite, prompting the introduction of a definite discourse referent, available to interpret subsequent anaphorically dependent definite temporal pronouns.

These considerations suggest that what it takes to understand a name, a pronoun or similar definite expressions is fundamentally the same whether they occur within or outside fiction. Central to understanding the shared feature is the notion of representation (as opposed to representation*), as essential to factual as to fictional discourse. However, the basic similarity goes along with a number of less basic dissimilarities.

\section{Names in fiction}

Fictional names are as readily introduced and understood as other expressions in fiction, and as names in non-fiction. Fictional names are distinctive in that typically there is nothing they represent*, though they represent people and places. Likewise, even in fiction, tenses and temporal adverbs represent times. What could be problematic?

One answer is that fictional names seem to occur in truths that apparently require that there genuinely are things they represent*, though things 
that do not belong to reality. Those who take this appearance at face value can be called realists about fictional names. Those who take the contrary position are irrealists. The paper up to this point has been intended as background for an irrealist view.

A standard problem for realists is that sentences like "Holmes" does not exist" strike us as true. Realists should predict that it is in fact false, or at least has a false reading. That is a tough problem; but realists may find some special story to deal with such cases, and go on to defend their position by appealing to various kinds of sentence that seem to pose problems for irrealists, for example, the following:

1. Internal: Holmes lived on Baker Street.

2. Authorial: Holmes was created by Conan Doyle.

3. Interfictional: Holmes is more cerebral than Christopher Robin.

4. Critical (metafictional): Holmes is more realistically portrayed than Hercule Poirot.

5. Cross-fictional: Holmes is famous.

A standard truth condition for subject-predicate sentences is this:

the sentence is true iff the subject expression refers* to something that the predicate expression is true of.

The notion of reference* appealed to in such a truth condition is the strong (relational) kind, as marked by the asterisk. Since fictional names typically don't refer* (though they do refer), the approach (extended also to twoplace relational sentences) treats none of the sentences in the above list as true. But intuitively they are all true. This is evidence for a realist approach to the semantics and ontology of fiction.

If the examples are really true, and the semantics of "Holmes" requires it to refer* (as opposed to merely referring), then there must exist such a thing as Holmes. True, he is not one of us; he is a "fictional character", with distinctive features that need to be explained. But, according to realists, fictional characters really exist, so there's a chance that we can regard the five sentences, along with countless others like them, as really true. Irrealism, according to realists, forces us to make the wrong predictions about the truth values of the sample sentences. 
Suppose Holmes really exists, as a feature of our reality. He cannot be an actual concrete human being, else we could shake his hand (or we could have done so if we had lived in the 19th century), and we all know we cannot do that. He must, rather, be either an actual abstract entity, or a concrete entity that is either non-existent or merely possible. All three options have been tried, but all three have problems. Here I give a sample problem for each option. ${ }^{6}$

Fictional characters are actual abstract entities Abstract things don't smoke pipes or literally live anywhere, so we cannot regard (1) ("Holmes lived on Baker Street") as truly predicating living on Baker Street of Holmes, regarded as an abstract entity. Rather, the theorist has to say that fictional abstract entities generate a predicational ambiguity: sometimes when we speak of them we speak of how the entities are in themselves, but sometimes we speak of what they encode or represent ${ }^{7}$. The first reading of the ambiguity works best for (2) above: Conan Doyle brought a certain abstract entity, Sherlock Holmes, into existence, just as signatories to a contract can bring a contract (an abstract entity) into existence (as in Thomasson 1999). The second reading of the ambiguity works best for (1) above: the abstract entity doesn't live anywhere, but represents or encodes the property of living on Baker Street (along with all the other properties attributed in the novels, like smoking a pipe and being a detective).

In normal cases of ambiguity, it's always possible to hear the other reading, even if it's inappropriate. Normally, one would understand the sentence "I went to the bank to catch a fish" as speaking of a river bank; but one can also hear the sentence as claiming that the speaker, presumably misinformed or in an unusual situation, went to a financial institution to catch a fish. So one ought to be able to hear (1) as false, falsely predicating living on Baker street as a property of an abstract entity in itself; and (2) as false, as claiming that the abstract entity represents Holmes as a creation of Conan Doyle. But these readings are not available. The abstract artifact

\footnotetext{
6 A fuller discussion can be found in Sainsbury (2010).

7 The relevant encoding or representing cannot be encoding* or representing*, so this realist cannot object to the tools exploited by the irrealist. If abstract entities can refer in the weak sense, why not say that names can do the same, a significant simplification?
} 
theory also has special trouble with "Holmes does not exist", for according to the theory the abstract entity exists and represents Holmes as existing.

Fictional characters are non-actual, merely possible, entities. If Holmes is a merely possible entity, which entity is he? The one who has all and only the properties attributed to him in the novels? The early novels were not about that man, because there was then no fact about which properties would be attributed later. The one who has all and only the properties attributed at a given stage? In that case, there is a new Holmes with every new attribution of a property. The realist who takes this route is hard pressed not to end up with too many Holmes's.

Fictional characters are actual non-existent entities I think there are many things that don't exist, like dragons and round squares (Sainsbury 2018: 59-61). Not everyone agrees; those who disagree will be even more reluctant to regard fictional names as referring to non-existents. The problem even for those who are ready to believe that there are things that do not exist is that non-existent entities cannot have existence-entailing properties, like living on Baker Street. This is something only existent things can do. ${ }^{8}$ Think how overpopulated Baker Street would become if we supposed that nonexistent people lived there! Or do they manage to live there while taking up no space at all?

These quick observations are not intended to do more than make the case for examining an irrealist view according to which our reality contains no fictional entities, abstract or concrete, actual, merely possible, or non-existent.

\section{Irrealism: Fiction without real fictional entities}

In speculating - explaining and planning — we typically envisage scenarios. These are not made less useful by sometimes referring to events or objects that do not exist. This is the model to apply to fiction.

8 The notion of existence-entailing properties is introduced by Forbes $(2006,46)$. (More exactly, he introduces its converse: existence-independent properties.) Smoking is an existence-entailing property. But don't dragons breathe fire (and so come close to smoking)? Not really. There are fables according to which dragons breathe fire, but the bare "Dragons breathe fire", uttered in a fully serious context, is not true.

Organon F 28 (1) 2021: 44-59 
The realist position described in the previous section presupposed that the truth of a subject-predicate or relational sentence consists in the subject expression referring* to something that satisfies the predicate. That's why the truth of examples (1)-(5) supposedly required the existence of Holmes. For "Holmes lived on Baker Street" to be true on this view, "Holmes" needs to refer* to an entity that lives on Baker Street. Hence, according to realists, we need to recognize the reality of fictional characters like Holmes.

We saw earlier that linguistic features can push us towards the "irrealist" notion of reference, as opposed to the "realist" notion of reference*. Pragmatic pressures may work hand-in-hand with these linguistic features to achieve the same effect. In planning and explaining I may at some point be interested not in "real" truth, but in how things are according to the plan or the explanation: truth relativized to a context. Planning a heist, I may wonder whether we will encounter any guards at that time of night. A companion in crime suggests we will not. "That's true" I exclaim, to myself or out loud. The notion of truth I am applying is relative to the plan. If we adopt another plan, or no plan at all, that does not make that very thought true, even if we would not have encountered any guards in this other scenario. The thought I have is relative to the scenario in which it occurs. Truth in this case is a matter of what would happen if we did adopt the plan. This relativization of truth is not special to fiction as such, for it is involved in speculation.

Similar mechanisms are at work in fiction. This is the explanation of the tendency we have to regard "Holmes lived on Baker Street" as true. It's true in, or relative to, the story, but is not true in fact, for there is no such person as Holmes. We all believe there is a distinction between fictional and real truth. If we make the distinction explicit, and then ask whether (1) is really true, only the uninformed would respond affirmatively. The slight inclination to register fictional truth as real truth evaporates when we encounter less well known fictional sentences, like the one about Selden quoted earlier from The House of Mirth. It's very unlikely that a standard reaction to that sentence would be that it's true.

"Holmes was created by Conan Doyle" (2), though it concerns fiction, is not fictionally true: no fiction of which I am aware, and certainly not the Holmes stories, makes this claim. Rather, the sentence is really true. The 
envisaged truth conditions for subject-predicate sentences (they are true iff the subject expression refers* to something that satisfies the predicate) entails that "Holmes" refers* to something satisfying the predicate "was created by Conan Doyle", and so entails that Holmes exists. (2) is really true, so Holmes really exists. Or so realists argue.

Let's consider what Doyle did to create Holmes. He did not act as the fictional Dr Frankenstein did, collecting body parts from the hospital and assembling them. Instead, he wrote words on the page. The creation of Holmes is derivative on the creation of the story. It amounts to no more than this: Doyle created a story according to which Holmes exists; and according to which Holmes is a detective of remarkable intellectual powers; and so on. These claims do not entail that "Holmes" refers* to anything. But they exhaust what it takes to have created Holmes. So (2) is really true, but does not entail that there is any such entity as Holmes.

This shows that we have to regard the envisaged reference*-involving truth conditions for subject-predicate sentences as restricted to existenceentailing-predicates. "Creates" in many contexts is existence-entailing. If I created a rose garden, then there has to be a rose garden that resulted from my labors. In fictional creation, there is an existence-entailing activity: I don't create a novel unless a novel comes into existence as a result of my labors. But there is also a non-existence-entailing aspect: the novel makes no claim to truth, and so does not require the existence of the things it represents. Conan Doyle did, in a sense, create Holmes. He did so by genuinely creating novels according to which there was a detective, Holmes, who lived on Baker Street, etc. Novels are real things, but they are things that represent rather than represent*.

Interfictional examples like (3) ("Holmes is more cerebral than Christopher Robin") are said by realists to be of the form Rab, and hence to require the existence of both Holmes and Christopher Robin for their truth. And so, in a way, they do. But we need to understand this within the framework of two ideas. One is that truth is relative, and the other is that stories, like testimonies, can be combined.

The relativity of truth I wish to point out is not intended in any postmodernist way. What is at stake is the manifest fact that planning, explaining, and speculative activities other than fiction, as well as fiction itself, can 
generate a framework for a relativized notion of truth: truth in the fiction, or in the speculation. Truth thus relativized may not coincide with absolute truth, truth in the world as it really is.

Consider a very ordinary planning dialog:

A: Are you going home for the holidays?

B: I'm not sure yet, but I think so.

A: Will you fly or drive?

B: I'll drive.

Suppose that, as it turns out, B can't get away for the holidays. Is his final remark in the dialog true or false? Either answer may be regarded as correct. Within the context of the dialog, it's true. B has a phobia about flying and always drives when it's feasible; so driving was the plan. But considered outside the context, it's false: B did not drive home for the holidays. B spoke sincerely when he said he would drive, and what he said was true, as assessed relative to what was presupposed at that stage in his conversation. But since he didn't in fact drive home, what he said is false, assessed independently of the local presuppositions of the discourse.

That is one element needed for understanding claims like (3). The other element is the possibility of combining testimonies. Imagine two witnesses testifying. One says that a suspicious-looking man ran east out of the bank. The other says that a suspicious-looking woman ran west out of the bank. Neither witness says anything that entails that two people ran out of the bank, but the two testimonies together entail this. We can think of fictions as like testimonies. The Holmes stories and the Christopher Robin stories arguably together entail that Holmes was more cerebral than Christopher Robin. Relative to the context framed by these two stories it is (on this view) true that Holmes is the more cerebral. But it is not true absolutely. All we are saying is that this is what must be so if both stories are true. But they are not really true, and really, (3) is not true either.

Critical examples like (4) ("Holmes is more realistically portrayed than Hercule Poirot", which is also interfictional) make explicit that fiction is being discussed by a critic. ${ }^{9}$ In such cases, we wish to regard the critic as

$9 \quad$ This might be the kind of thought intended by (3): that Holmes is portrayed as more cerebral than Robin. 
having said something true (or false) about the real world, which of course contains the fiction as a part. Such remarks are to be evaluated as about fictions, not as within them. The present example turns on the intensional verb "portrayed", a verb that is not existence-entailing in its object position: $\mathrm{x}$ portrays $\mathrm{y}$ does not entail that $\mathrm{y}$ exists. The Unicorn Tapestries portray unicorns, but it does not follow that unicorns exist. Likewise, the portrayals of Holmes and Poirot do not entail that either detective exists. Portrayal is a species of representation, not representation*.

In sentences like "Holmes is famous" (5) a relation seems to be affirmed between fiction and reality. Holmes' fame is fame among us: we are related to Holmes by his fame, and realists will say that if Holmes is famous among us, he must exist just as we must exist.

To be famous is to be regarded or thought of in a certain way by many people. Regarding or thinking of are intensional verbs, and are not existenceentailing in their second position: that $x$ regards or thinks about $y$ does not entail that $y$ exists. Hence things that do not exist can be famous. Pegasus is a famous, though mythical, horse. Vulcan is a famous, though non-existent planet. Being famous is not existence-entailing, and so an irrealist can happily regard (5) as true.

In conclusion, once we appreciate the ubiquity in our thought and talk of reference, and related notions, as opposed to reference*, the arguments that seemed to favor realism about fictional entities lose all persuasive value. We can happily combine commonsensical realism about fictions (novels, plays), which of course really exist, with irrealism about the fictional characters, people and places they portray, which typically do not.

\section{References}

D'Ambrosio, Justin. 2019 "Semantic Verbs Are Intensional Transitives". Mind 128: 213-248. https://doi.org/10.1093/mind/fzx029

Forbes, Graeme. 2006. Attitude Problems. Oxford: Oxford University Press.

Kamp, Hans. 1981. "A Theory of Truth and Semantic Representation". In Formal Methods in the Study of Language, volume 1, edited by Jeroen Groenendijk, Theo M. V. Janssen, and Martin Stokhof, 277-322. Amsterdam: Mathematical Centrum.

Kamp, Hans, and Reyle, Owe. 1993. From Discourse to Logic. Dordrecht: Kluwer Academic Publishers. 
Kartunnen, Laurie. 1976. "Discourse Referents". In James D McCawley (ed) Syntax and Semantics vol \%: Notes from the Linguistic Underground: 363-85. New York: Academic Press:

Sainsbury, Mark. 2010. Fiction and Fictionalism. Abingdon: Routledge.

Sainsbury, Mark. 2018. Thinking About Things. Oxford: Oxford University Press.

Thomasson, Amie. 1999. Fiction and Metaphysics. Cambridge: Cambridge University Press. 